Respirator-Cartridge Filter Efficiency under Cyclic and Steady-Flow Conditions 
This report was prepared as an account of work sponsored by the United States Government. Neither the United States nor the United States Atomic Energy Commission, nor any of their employees, nor any of their contractors, subcontractors, or their employees, makes any warranty, express or implied, or assumes any legal liability or responsibility for the accuracy, completeness or usefulness of any information, apparatus, product or process disclosed, or represents that its use would not infringe privately owned rights.

Printed in the United States of America. Available from National Technical Information Service

U. S. Department of Commerce 5285 Port Royal Road Springfield, Virginia 22151

Price: Printed Copy $\$ 3.00$; Microfiche $\$ 0.95$ 


\title{
Respirator-Cartridge Filter Efficiency under Cyclic and Steady-Flow Conditions
}

by

\author{
Ronald G. Stafford \\ Harry J. Ettinger \\ Thomas J. Rowland*
}

"Permanent address: Assuciated Western University Fellow,

University of Arkansas, Fayetteville, Arkansas 72701.

Work supported by the AEC Division of Biology and Medicine. 
RESPIRATOR-CARTRIDGE F'IITER EFFICIENCY

UNDER CYCLIC AND STEA.JY-FLOW CONDITIONS

by

Ronald G. Stafforc, Harry J. Ettinjer, and Thomas J. Rowland

\section{ABSTRACT}

Respirato: filter cartridges are routinely tested under steady-flow conditions to provide a basis for predicting their future performance under cyclic-flow conditions produced by various human breathing efforts. Because filter efficiency is a function of velocity, as well as particle size, it was considered necessary to perform tests to define aerosol penetration through respirator filter cartidges under both cyclic- and steady-flow conditions. These tests effectively evaluate the adequacy of existing steady-flow test procedures. A breathing pump was used to simulate different human breathing patterns during work rangirg from sedentary to extra heavy. Steady-flow conditions were identical to those recommended by the Bureau of Mines for permissikility tests of respiratory protective devices. solid, monodisperse, polystyrene latex aerosols ranging from 0.176 to $2.02 \mu \mathrm{m}$ in size, as well as liquid monodisperse $0.3-\mu \mathrm{m}$ dicctyl phthalate were used as the test aerosols. A method was devised to sample during cyclic flow without altering the flow pattern by sampling continuously downstream from the respirator cartridge. Experimental data obtained during steady and cyclic flow are compared as a function of aerosol. size, breathing pattern, and type of aerosol. Theoretical steady-flow aerosol penetration through fibrous filters is compared to penetrations associated with variable velucities produced during cyclic flow.

\section{INTRODUCTION}

Practical and theoretical performance of filtration media used in respirator cartridges for personal protection has usually been evaluated under steady or constant flow conditions. ${ }^{1}$ The U.S. Department of the Interior, Bureau of Mines, specification under schedule 21 B for permissibility testing of dust, fume, and mist respirator filter cartridges is based on a steady flow rate of 32 liters/min, except for those respirators designed for dual filters tested at 16 liters $/ \mathrm{min} .{ }^{2}$ Tests run under steady-flow conditions are used to predict future performance of filter cartridges under varied cyclic flow conditions. Velocity of an aerosol stream passing through a respirator filter as normally used varies from zero to some maximum value, and back to zero, because of the normal human breathing pattern. The variation in air velocity through the filter approaches a rectified sinusoidal wave form. Because filter efficiency is a function of velocity, as well as particle size, a test system was designed and tests were performed to define aerosol penetration through respirator filter cartridges during cyclic 
TABLE I

SILVERMAN'S MEASUREMENTS AT VARIOUS WORK RATES

\begin{tabular}{|c|c|c|c|c|c|c|}
\hline \multirow[b]{2}{*}{ Measurement } & \multirow[b]{2}{*}{$\begin{array}{c}\text { Seden- } \\
\text { tary } \\
\end{array}$} & \multicolumn{5}{|c|}{ Work Rate $(\mathrm{kg}-\mathrm{m} / \mathrm{min})$} \\
\hline & & 208 & 415 & 622 & 830 & 1107 \\
\hline $\begin{array}{c}\text { Subjects } \\
\text { tested }\end{array}$ & 29 & 12 & 14 & 12 & 59 & 46 \\
\hline $\begin{array}{l}\text { Pulse } \\
\text { rate/min }\end{array}$ & 73 & 105 & 116 & 128 & 158 & 166 \\
\hline $\begin{array}{l}\text { Respiration } \\
\text { rate/min }\end{array}$ & 14.6 & 21.2 & 22.7 & 23.0 & 30.4 & 34.8 \\
\hline $\begin{array}{l}\text { Minute } \\
\text { volume, } \\
\text { liters }\end{array}$ & 10.3 & 20.8 & 29.9 & 37.3 & 54.7 & 75.3 \\
\hline $\begin{array}{l}\text { Maximum } \\
\text { inspiratory } \\
\text { flow, } \\
\text { liters/min }\end{array}$ & 40 & 63 & 84 & 100 & 149 & 194 \\
\hline $\begin{array}{l}\text { Maximum } \\
\text { expiratory } \\
\text { flow, } \\
\text { liters/min }\end{array}$ & 32 & 58 & 85 & 107 & 154 & 211 \\
\hline
\end{tabular}

flow simulating different human breathing patterns, and during steady flow.

Silverman defined six different working levels using a number of subjects performins tests on a bicycle ergometer. ${ }^{3}$ He measured cyclic flow rate, respiration rate, pulse rate, and a number of other physiological parameters. Work rate varied from sedentary work through work levels of 1,500 , $3,000,4,500,6,000$, and $8,000 \mathrm{ft}-1 \mathrm{~b} / \mathrm{min}$ $(208,415,622,830$, and $1,107 \mathrm{~kg}-\mathrm{m} / \mathrm{min})$. An extra heavy work level is considered to be $830 \mathrm{~kg}-\mathrm{m} / \mathrm{min}$ but few people can attain $1,107 \mathrm{~kg}-\mathrm{m} / \mathrm{min}$. Table I shows some of the parameters measured at the various work rates. ${ }^{3}$

In 1961, Jordan and Silverman reported the effect of cyclic air flow on fiberglass filter efficiency. 4 Their study utilized an aerosol with a count median diameter of $0.78 \mu \mathrm{m}$ and a geometric stancard deviation of 1.13. Their results indicate that aerosol penetration through filters during cyclic flow with a given time-averaged mean velocity could not be predicted from penetration obtained during steady flow. Aerosol penetration during cyclic flow was lower at low time-averaged mean velocities, and higher at high time-averaged mean velocities, than penetration measured at corresponding steady-flow velocities.

A preliminary comparative study of cyclic and steady-flow tests was performed ai Los Alamos. 5 Cyclic flow was produced by a calibrated scott breathing pump which is a cam-driven piston and cylinder-type mechanical breather. ${ }^{6}$ At the Los Alamos scientific Laboratory (LASL), the preliminary study was limited to cyclic flow tests simulating a work load of $830 \mathrm{~kg}-\mathrm{m} / \mathrm{min} .5$ If the filter cartridge being tested was designed for use on respirators requiring one or two filters, steady-flow tests were performed at 32 or 16 liters/min, respectively. These preliminary tests used a spherica? uranine methylene-blue aerosol generated by a spinningdisk aerosol generator ${ }^{7}$ that fiactionates droplets into two size ranqes, primary and satellite particles. The monodisperse primary aerosols ranged from 1 to $3 \mu \mathrm{m}$, whereas the satellite aerosols consisted of submicron particles with a bimodal size distribution. The 1-to-3- $\mu \mathrm{m}$ monodisperse aerosol particles generally produce higher penetration during cyclic flow at a work rate of $830 \mathrm{~kg}-\mathrm{m} / \mathrm{min}$. Because of the complex bimodal distribution of the satellite aerosol, no conclusive information could be drawn for the submicron aerosol tests.

Austria, the Federal Republic of Germany, Italy, and Yugoslavia have established respirator filter quality-control test procedures incorporating cyclic flow to simulate human breathing patterns. ${ }^{8}$ The U.S. Bureau of Mines has approached cyclic flow with a test procedure for evaluating entire respirator performance in their "man-tests" that requires sampling a dioctyl phthalate (DOP) aerosol from within and outside of a mask worn by an individual. 2 This test is designed to evaluate both respirator filters and the facial fit of mask. An oversimplification in this test results since 8 liters/ min is continually sampled from within the mask. Therefore, during inhalation, the 
filtration velocity is the sum of that imposed by the individuals breathing pattern and an additional velocity resulting from the constant 8-liter/min sampling rate. This test condition does not represent respirator performance during actual lise. because 0.1- to 2,0-ur. particles are significantiy deposited within the respi-

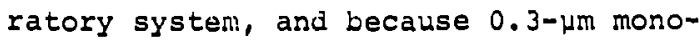
disperse liquid DOP has been accepted as a standard test aerosol in the Urited States, 2 a study was initiated to define filter efficiency under cyclic and steady flow using monodisperse solid and liquid submicron aerosols. It is desirable to define specific test procedures in terms of aerosol particle size, air velocity, and type of aerosol that produce maximum penetration for each type of filter and proposed use.

\section{EQUIPMENI}

We used Dow Chemical Company polystyrene latex particles (PSL) in essentially monodisperse ${ }^{9}$ size ranges from 0.176 to $2.02 \mu \mathrm{m}$ as the solid test aerosol. We used monodisperse $0.3-\mu \mathrm{m}$ DOP as the liquid test aerosol because of its size, the vast amount of previous filtration information obtained using $i t$, and its possible selection as a standard test aerosol for evaluating respirator performance. Because instrumentation techniques have improved vastly over the last few years, we were able to benefit from the apparent limitations in previous studies, and could develop a unique test system to duplicate man's breathing pattern through respirator filters more accurately. An aerosol-generation test system (Fig. 1) used in previous experiments was adequate for the

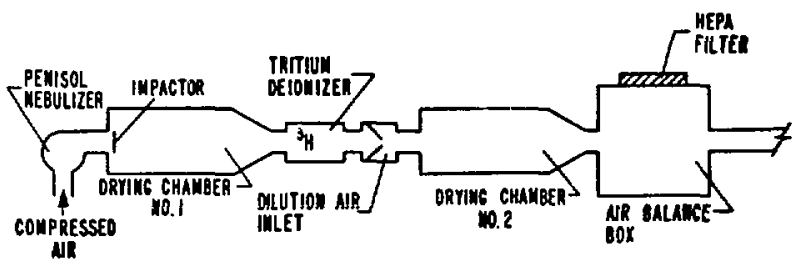

Fig. 1. Aerosol generation system. cyclic-flow tests. The PSL aerosol was generated from three Hudson oxygon Therapy Sales Company Pen-i-sol nebulizers and then impacted on disks to collect or break up agglomerates produced by the nebulizer. The aerosol then traversed the first drying chamber to a tritium deionizer to reduce any charge incurred during nebulization. ${ }^{10}$ The tritium source consisted of two sheets of tritlated foil $1 / 4$ in. apart and having 4 $\mathrm{Ci}$ of tritium adsorbed in a titanium layer (U.S. Radium Corporation, Morristown, New Jersey). The tritium creates charge equilibrium on the PSL aerosol particles by secondary ionization in air and helps prevent agglomeration by creating a Boltzman equilibrlum charge distribution on the aerosol population. 11 Aerosol-particle net charge for $0.312-\mu \mathrm{m}$ and smaller particles was measured with a parallel plate sapacitor. The deionizer was found to reduce the latex aerosol charge on the $0.312-\mu \mathrm{m}$ particles by 908 and that on the $0.176-\mu \mathrm{m}$ particles by more than 988. ${ }^{12}$ Aerosol charge for 0.312$\mu \mathrm{m}$ particles was found to be 0.7 electron charges per particle after neutralization. The experimental method we used to measure aerosol charge made it impractical to try to measure charge on particles larger than $0.312 \mu \mathrm{m}$ because of their lower electric mobility ${ }^{11}$ and because of difficulties in constructing longer parallel plates. The concentration of single particles as determined by electron microscopy ranged from 85 to 1008 for all sizes.

After the tritium deicnizer, dilution air entered the system and the aerosol traversed a second drying tube. The aerosolgeneration system and the test system were joined by an air-balance box to ensure balanced air flow between the two. If DOP was used in place of polystyrene latex, it was introduced into the coupling box. DOP was generated from a $Q-127$ respirator-filter canister tester. ${ }^{13}$ Tris unit heats DOP to $172^{\circ} \mathrm{C}$ and condenses the vapor with cooler dilution air to produce a relatively monodisperse aerosol $\left(\sigma_{\mathrm{g}} \leqq 1.2\right)$. Particle size 


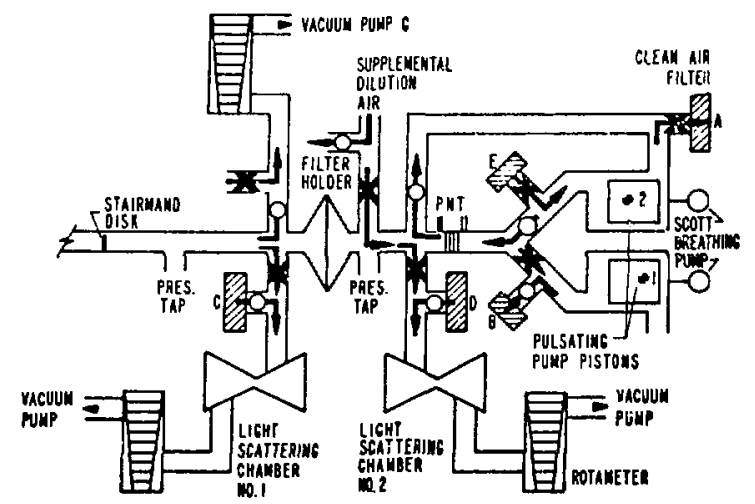

Fig. 2. Air sampling system.

was kept at $0.3 \mathrm{\mu m}$ by controlling the temperature of the dilution air. DOP size was routinely monitored with an electronic "OWL" that measures the polarization ratio of light scattered at $90^{\circ}$ by the aerosol. 14 Confirmation of aerosol size indicated by the OWL was obtained using the spiral centrifuge aerosol spectrometer.

Figure 2 shows the air-sampling test system. The aerosol entered a copper tube containing a Stairmand disk to ensure proper mixing ahead of the filter holder. The scott breathing purnp was used to simulate human breathing patterns during various work efforts. A number of "guillotine" Low-impaction solenoid valves, represented by X's and $O^{\prime} s$ in Fig. 2, minimized aerosol loss. 15 Conventional solenoid valves were undesirable because of the high loss due to impaction with this type of valve. The guillotine valve is shown in Fig. 3. Surgical tubing passes between a solenoidactuated pincher bar and a flat pressure base plate. The hose is kept loosely in position by retainers on each side of the pincher. Direct-current energizing of the solenoid effectively pinches the hose shut. When the assembly is properly adjusted, no leakage can be detected with 11 in. of positive pressure on the tubing. This is well above the usual air pressure of the scat.. tering-chamber system. When de-energized, the loosely guided pincher bar is held up by the resilience of the tubing with no perceptible dimpling in the line. The value system was designed so that sampling would occur only during the inhalation cycle. This was accomplished by switches at the extremes of the pistons on the breathing pump.

The aerosol concentration on each side of the filter was analyzed using two LASLdesigned light-scattering photometers. 15 The photometers were calibrated against each other with identical aerosols on ali scales to verify that their responses and linearities were identical. These photometers gave us an order of magnitude more sensitivity than corumercially available instruments.

In Fig. 2 each guillotine valve is marked with an $\mathrm{X}$ or an 0 . The $\mathrm{X}$ valves are open during inhalation and closed during exhalation. The o valves are closed during inhalation and open during exhalation. To understand the air-flow patterns, one must know what occurs during both inhalation and exhalation.

During inhalation, air is drawn through the filter by piston No. 1 of the breathing pump (Fig. 2). Fiston No. 2 is filled with clean air through filter $E$ and air in back

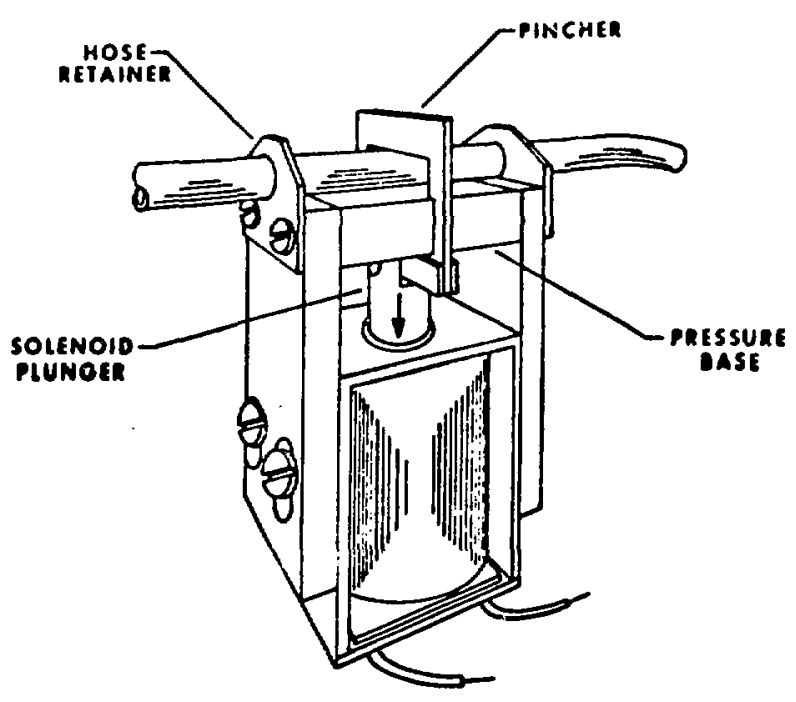

Fig. 3. Solenoid valve. 
of the piston is pushed out through an inline clean-air filter (A). Both upstream and downstream photometers sample the airstrean at a flow rate of 8 liters/min. An additional (supplemental air) $8 \mathrm{liters/ \textrm {min }}$ is introduced radially downstream from the test filter and in the direction of the downstream photometer. This supplies the sampling flow for the downstream photometer and closely approximates a flow pattern applied by an individual's breathing through a respirator filter cartridge. This supplementary flow produces a variable downstream dilution factor by changing the air flow throughout the inhalation cycle, and does not allow direct computation of aerosol penetration through a filter. Penetration can be determined if air-flow rate is known at all points throughout the inhalation cycle. This method of computation is explained in Sec. IV. Air flow and test filter pressure drop is continuously monitored by a pneumotachograph (PNT) connected to a differentialFressure transducer that relays an electrical signal through an amplifier circuit to both a 12-channel strip-chart recorder and an automatic data-acquisition system that will be explained later.

During exhalation, piston No. 2 of the breathing pump introduces clean air previously received through filter $E$ during inhalation back towards the test filter, pushing aerosol-contaminated air out of the system through filter $A$. Air that was drawn into piston No. 1 during inhalation is discharged through an in-line filter (B) to the room atmosphere. Clean air is drawn through in-line filters (C, D) to purge both light-scattering photometers. Aerosolladen air in front of the test filter is remo:ed (G) to prevent buildup of aerosol concentration during exhalation.

A three-channel digital-data acquisition system was developed to record, continually, data from the two light-scattering pnotometers and the pneumotachograph flow meter. Pressure drop can also be recorded in place of one of the photometer signals.
The data-acquisition system records the si:nal on a Tally Corporation Model P-120 tape punch. Data recorded on the tape are conducive to computer analysis.

\section{TEST PROCEDURE}

Two types of respirator filter cartridges and one flat air-sampling medium were tested under cyciic-flow work rates of 830,622 , and $415 \mathrm{~kg}-\mathrm{m} / \mathrm{min}$. Each was also tested under a steady-flow rate of 16 liters/min. Preliminary cyclic-flow tests using respirator filter cartridges indicated that poor guality control made it impossible to duplicate any results reliably. Therefore we selected two types of cartridges, MSA Type-S and Welsh 7500-7, and bought a number of cartridges so that we could perform our own quality-control tests. We chose these two types of filters because they gave enough aerosol penetration to allow us to measure concentrations downstream from the filter effectively. We chose whatman 41 as the flat air-sampling medium for testing. All respirator cartridges were

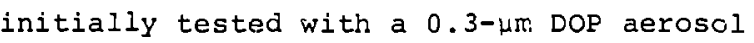
at a steady-flow rate of 15 liters/min. All MSA Type-S cartridges with a penetration of $1.58 \pm 0.58$ and Welsh 7500-7 cartridges with a penetration of $12.5 \% \pm 2.5 \%$ were selected for the cyclic- and steady-flow tests. Polystyrene latex particle sizes of $0.176,0.234,0.312,0.5,0.79,1.011$, and $2.02 \mathrm{\mu m}$, as well as $0.3-\mu \mathrm{m}$ DOP, were used as the test aerosols. Three different filters of each type were tested using each particle size at every cyclic-flow work rate and under steady-flow conditions. Before testing, each filter's pressure drop and the test flow rate were recorded on the strip-chart recorder and data-acquisition system. The aerosol was then introduced, and aerosol penetration and air-flow meas-urements were recorded for 5 to 10 breaths. At the end of each test run, filter pressure drop was again recorded to determine if the filter had loaded during the test. 
TABLE II

MAXIMUM AND TIME-AVERAGED MEAN FLOWS THROUGH VARIOUS FILTERS

\begin{tabular}{|c|c|c|c|c|c|}
\hline $\begin{array}{l}\text { Eilter } \\
\text { 'Iype }\end{array}$ & $\begin{array}{l}\text { work Rate } \\
(\mathrm{kg}-\mathrm{m} / \mathrm{min})\end{array}$ & $\begin{array}{c}\text { Max Flow } \\
\text { Through } \\
\text { Filter } \\
\text { (1iters/min) } \\
\end{array}$ & $\begin{array}{c}\text { Time AV } \\
\text { Mean Flow } \\
\text { Through } \\
\text { Filter } \\
\text { (liters/min) }\end{array}$ & $\begin{array}{c}\text { Max Vel } \\
\text { Through } \\
\text { Filter } \\
\text { (cm/sec) } \\
\end{array}$ & $\begin{array}{c}\text { Time AV } \\
\text { Mean Vel } \\
\text { Through } \\
\text { Filter } \\
(\mathrm{cm} / \mathrm{sec})\end{array}$ \\
\hline visA 'L'pe "S" & 415 & 42 & 29.69 & 2.69 & 1.90 \\
\hline MSA Type "S" & 622 & 50 & 35.35 & 3.21 & 2.27 \\
\hline MSA Trpe " $S$ " & 830 & 75 & 53.03 & 4.81 & 3.40 \\
\hline welsh 7500-7 & 415 & 42 & 29.69 & 15.32 & 10.83 \\
\hline belsh $7500-7$ & $E<2$ & 50 & 35.35 & 18.23 & 12.89 \\
\hline Welsh $7500-7$ & 830 & 75 & 53.03 & 27.35 & 19.34 \\
\hline Whatran 41 & 415 & 42 & 29.69 & 18.29 & 12.93 \\
\hline Whatman 41 & 622 & 50 & 35.35 & 21.78 & 15.40 \\
\hline Whatran 41 & 830 & 75 & 53.03 & 32.67 & 23.10 \\
\hline
\end{tabular}

MSA "Ype "S" filter area $=260 \mathrm{~cm}^{2}$

Welsi 7500-7 filter area $=45.7 \mathrm{~cm}^{2}$

Whatman 41 filter area $=38.26 \mathrm{~cm}^{2}$

Besause there was a variable dilution factor throughout the entire inhalation period, penetration was calculated at 10 equally spaced times throughout the breath. The number of particles passing the filter per unjt time is equal to the true concentration $\left(\mathrm{C}_{T}\right)$ times the instantaneous flow rate ( () ) at that time. Because the flow rate changes continually throughout the cyclic-flow cycle, the concentration of particles also changes. If 8 liters/min were added downstream, the actual concentraticn would be changed to some apparent concertration $\left(C_{A}\right)$; therefore, the following relationship should hoid true to calculate ine actual concentration.

$$
r_{T} Q=C_{A}(Q+8) \text {, }
$$

and silving for $C_{T_{8}}$

$$
z_{\mathrm{T}}=c_{\mathrm{A}}\left(1+\frac{8}{0}\right) \text {. }
$$

This formula was also used to check for complete mixing of the 8-liter/min dilution air with the aerosol concentration before the balancing air was added. If the calculatec concentration matched the measured conceintration, we were confident of proper mixing between the aerosol passing the filter and the supplementary clean air introduced downstream from the filter. In all cases, complete mixing was verified by these tests.

Every data point for cyclic flow on all of the following graphs represents the average penetrations of each of three filters during several individual breaths. Analysis of each breath consisted of at least 10 penetration measurements averaged to give the average aerosol penetration throughout that breath. Table II presents the maximum and time-averaged mean flow through the filter as well as the associated velocities for each type of filter tested. Velocities through Welsh-7500-7 and Whatman 41 filters at corresponding flow rates are approximately six times those through MSA Type-S filters. This is because MSA Type-s filters are pleated to provide maximum filtration area and minimum pressire drop.

\section{RESULTS}

Figure 4 shows aerosol penetration as a function of particle size for MSA Type-S 


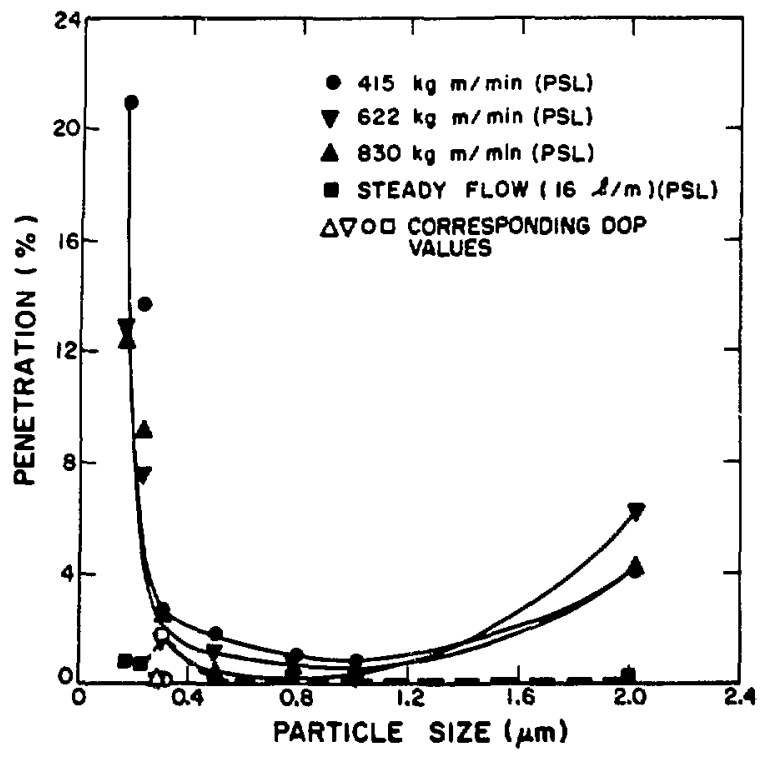

Fig. 4. Aerosol penetration of MSA Type-S filter cartridges at cyclic-flow work rates of 415,622 , and 830 $\mathrm{kg}-\mathrm{m} / \mathrm{min}$.

filter cartridges at cyclic-flow work rates of 415,622 , and $830 \mathrm{~kg}-\mathrm{m} / \mathrm{min}$ and a steadyflow rate of $16 \mathrm{liters} / \mathrm{min}$. There is no significant difference in aerosol penetration as a function cyclic-flow work rate except at the smailer particle sizes $(<0.3$ $\mu \mathrm{m})$. This curve rises so rapidly at the smaller size ranges that it may be questionable to suggest a significant change in penetration for different work rates, even here. Penetration by polystyrene latex under cyclic-flow work conditions varies from 0.5 to 218 throughout the entire aerosol size range tested. Penetration values for $0.3-\mu m$ DOP were less than 0.28 for all cyclic-flow conditions; therefore, use of this DOP aerosol would considerably overestimate this filter's effectiveness in removing solid particulates. Although theoretical single-fiber filtration-efficiency steady-flow equations predict that $0.3 \mu \mathrm{m}$ is the particle size producing maximum penetration, 16 this is not the particle size that produces maximum penetration of this filter during cyclic flow. Figure 4 also shows filter-cartridge efficiency as a function of particle size for a steady-flow rate of 16 liters/mir. Maximum penetration occurs at a particle size of approximately 0.3 $\mu \mathrm{m}$ which is consistent with theoretical single-fiber predictions. 16 However, all steady-flow penetration values are well below those for cyclic flow, indicating that this steady-flow test, used by the Bureau of Mines under Schedule $21 \mathrm{~B}^{2}$ overestimates the effectiveness of the respirator filter as it would normally be used. It especially overestimates the filter effectiveness at particle sizes below $0.3 \mu \mathrm{m}$ and above $1.2 \mu \mathrm{m}$. Particles larger than $1.2 \mu \mathrm{m}$ are of considerable significance because of their mass which is still respirable. 17 Liquid $0.3-\mu \mathrm{m}$ DOP penetration during steady flow approximates that of solid polystyrene latex under the same conditions.

Apparently, as will be shown later, a different particle size produces maximum penetration of each type of filter during cyclic flow. Figure 4 indicates that $0.176-$ $\mu m$, or smaller, particles give maximum penetration through MSA Type-s filters during cyclic flow. Because of limited aerosolgeneration techniques, we were unable to produce a PSI aerosol smaller than $0.176 \mu \mathrm{m}$ owing to excessive aerosol agglomeration. We expected that filter penetration would decrease owing to Brownian diffusion somewhere below this size range. However, during cyclic flow particles probably never reach zero velocity because of the short time they experience zero flow, and because some kinetic energy is maintained by the particles throughout the cycle. The kinetic energy of particles larger than $1.0 \mu \mathrm{m}$ may cause the increase in penetration shown in Fig. 5: If this kinetic energy is greater than the sum of forces that could cause collection, we would expect the particle to penetrate through the filter. There would, of course, be some particle size large enough that penetration would again drop to zero. 


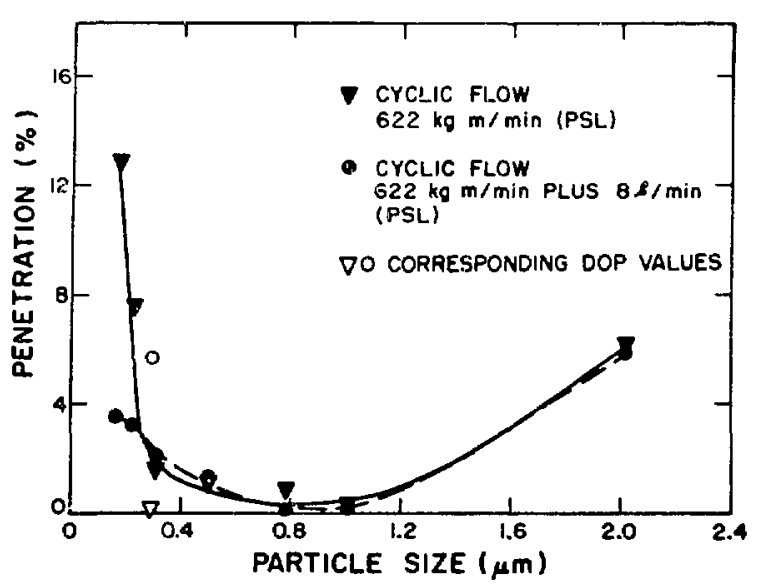

Fig. 5. Aerosol penetration of MSA Type-S filter cartridges at cyclic-flow work rates of $622 \mathrm{~kg}-\mathrm{m} / \mathrm{min}$ and 622 $\mathrm{kg}-\mathrm{m} / \mathrm{min}$ plus 8 liters/min.

Figure 5 shows aerosol penetration of MSA Type-s filter cartridges, with and without the air balancing system, as a function of particle size at a cyclic work rate of $622 \mathrm{~kg}-\mathrm{m} / \mathrm{min}$. 'L'he proposea Bureau of Mines man test specifies, under schedule $21 \mathrm{~B}$, that a sample at 8 liters/min should be withdrawn continuously from inside the mask during these tests. This imposes a higher velocity through the filter during inhalation and could keep the exhalation valve of the respirator mask closed until the man's exhalation rate became greater than 8 liters/min. The air-balancing system of our experimental apparatus more closely approximates a "true" breathing pattern. Figure 5 shows that this air balancing has little effect on MSA Type-s filter cartridges except for polystyrene latex particles much smalles: than $0.312 \mu \mathrm{m}$, at which point the raan test may indicate a considerably lower penetration than that to be expected during actual use. DOP gives an approximately $6 \%$ difference in penetration during simulated man tests and during true cyclic flow, thereby providing a conservative test. Again, as we will see with other filters, we would expect penetration to decrease at some smaller particle size, and $0.176-\mu \mathrm{m}$
TABLE III

PLEATED-CARTRIDGE PRESSURE DROP VS FILTER-DISK PRESSURE DROP

Cartridge ${ }^{a}$

Car- $\Delta \mathrm{P}$-Cartridge tridge Holder $\Delta \mathrm{P}$

\begin{tabular}{|c|c|c|c|}
\hline $\begin{array}{c}\text { tridge } \\
\text { No. }\end{array}$ & $\begin{array}{l}\text { Holder } \triangle P \\
\left(\text { in } \mathrm{H}_{2} \mathrm{O}\right)\end{array}$ & $\Delta P$ & $\begin{array}{l}\text { Disk } \\
\left(\text { in } \mathrm{H}_{2} \mathrm{O}\right)\end{array}$ \\
\hline 92 & 0.603 & & 0.405 \\
\hline 93 & 0.670 & & 0.363 \\
\hline 94 & 0.595 & & 0.354 \\
\hline
\end{tabular}

\begin{tabular}{c}
$\frac{\text { Cart. } L P}{\text { Disk } 1 \mathrm{P}}$ \\
\hline 1.489 \\
1.846 \\
1.681 \\
\hline$=1.672$
\end{tabular}

a Cartridge air-flow rate $=85$ liters $/ \mathrm{min}$ Cartridge air velocity $=5.45 \mathrm{~cm} / \mathrm{sec}$

$\mathrm{b}_{\mathrm{Disk}}$ air-flow rate $=12.6$ liters $/ \mathrm{min}$ Disk air velocity $-5.45 \mathrm{~cm} / \mathrm{sec}$

aerosol probably approaches the size for maximum penetration.

Because MSA Type-s cartridges contain pleated filters, we needed to know whether the entire filter area was being used effectively. If it is, we would expect the same pressure drop using the cartridge at the calculated filtration velocity and using a circular disk of the medium at this same incident velocity. We selected three MSA Type-S filter cartridges and performed these tests. The pressure-drop data in Table III were derived from tests of the e.tire cartridge, the cartridge holder without the filter medium, and the filter disk from the medium in each cartridge. These data indicate that pressure drop caused by the cartridge filter medium is a factor of 1.67 greater than that produced by the disk, indicating that the entire pleated area does not experience the same filtration velocity. This suggests that a more effective filterpleating design would be desirable to minimize pressure drop.

Figure 6 shows aerosol penetration of Welsh 7500-7 filter cartridges as a function of particle size at cyclic-flow rates of 415,622 , and $830 \mathrm{~kg}-\mathrm{m} / \mathrm{min}$, and a steadyflow rate of 16 liters/min. Steady flow at 16 liters/min shows the classical separation of diffusion and impaction filtration mechanisms, and the maximum penetration is by 


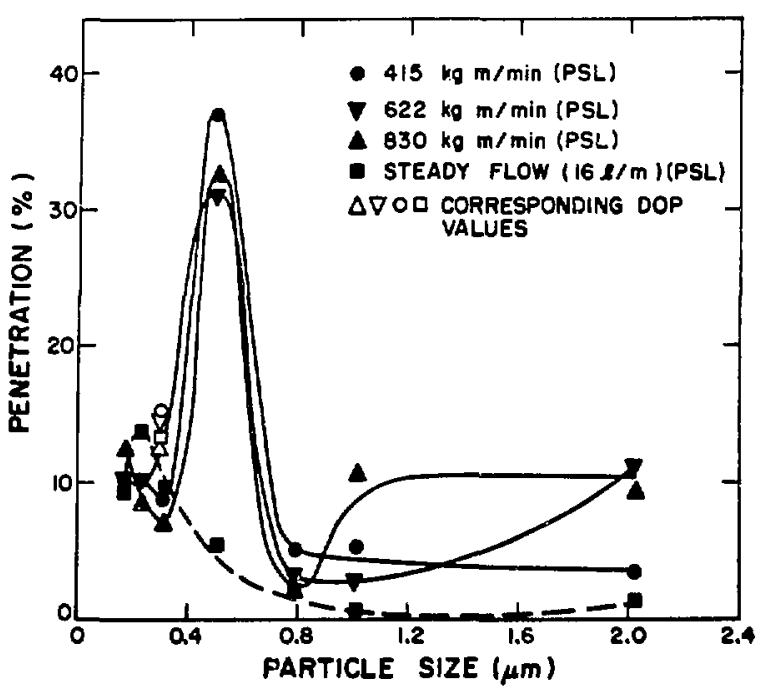

Fig. 6. Aerosol penetration of Welsh 7500-7 filter cartridges at cyclic-flow work rates of 415,622 , and 830 $\mathrm{kg}-\mathrm{m} / \mathrm{min}$.

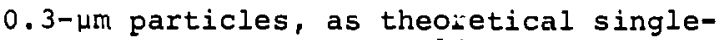
fiber equations predict. ${ }^{16}$ During cyclic flow at all work rates, predominant maximum penetration is by $0.5-\mu \mathrm{m}$ particles. Penetrations vary from 2.5 to $38 \%$ throughout the entire particle-size range tested. There are no significant differences in penetration among the three different cyclic-flow work rates for particle sizes below $0.8 \mu \mathrm{m}$; however, above $0.8 \mathrm{\mu m}$ penetration increases at the two higher work rates. At $830 \mathrm{~kg}-\mathrm{m} /$ min, an increased penetration by $1.01-\mu \mathrm{m}$ particles is apparent but at $622 \mathrm{~kg}-\mathrm{m} / \mathrm{min}$ there is no increase until we use 2.02-um particles. This follows the kinetic energy hypotinesis suggested previously. The kinetic energy of $1.011-\mu \mathrm{m}$ particles is great enough to overcome the filtration forces at $830 \mathrm{~kg}-\mathrm{m} / \mathrm{min}$ but not at the two lower cyclic-flow work rates. At $622 \mathrm{~kg}-\mathrm{m} / \mathrm{min}$, the kinetic energy of 2.02-um particles is, again, large enough to overcome the filtration mechanisms, but at $415 \mathrm{~kg}-\mathrm{m} / \mathrm{min}$ it is not. At $415 \mathrm{~kg}-\mathrm{m} / \mathrm{min}$, the velocity does not seem great enough to supply enough kinetic energy to the larger size particles. Again, particles larger than $1.0 \mu \mathrm{m}$ are of significant concern because of their much greater mass compared to submicron particles.

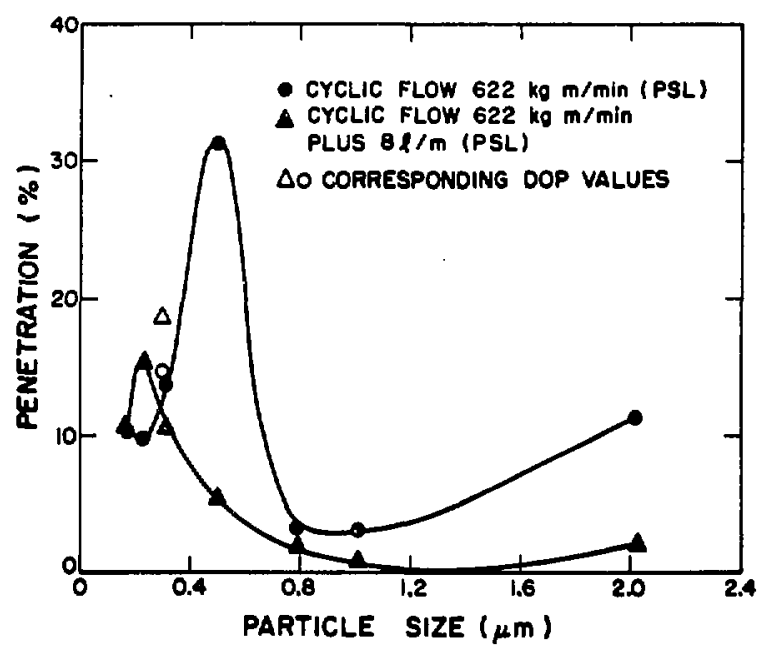

Fig. 7. Aerosol penetration of Welsh 7500-7 filter cartridges at cyclic-flow work rates of $622 \mathrm{~kg}-\mathrm{m} / \mathrm{min}$ and 622 $\mathrm{kg}-\mathrm{m} / \mathrm{min}$ plus 8 liters $/ \mathrm{min}$.

Because of the penetration spike at $0.5 \mu \mathrm{m}$ during cyclic-flow tests, it appears that 0.3-um DOP provides an underestimate of aerosol penetration of Welsh 7500-7 filters under steady-flow conditions. Steady flow at any of the particle sizes tested is not a reliable test method for this filter as it will be used on a respirator.

Figure 7 shows the relationship of true cyclic flow to cyclic flow plus an 8-liter/ min sampling rate (man-test situation) at a work rate of $622 \mathrm{~kg}-\mathrm{m} / \mathrm{min}$. When the balancing-air system is used to produce true cyclic flow, penetrations are significantly higher using particles larger than $0.3 \mu \mathrm{m}$. This indicates that proposed man-test techniques will overestimate the effectiveness of filter performance. Peak penetration occurs using $0.3-\mu \mathrm{m}$ particles without the air-balancing system. DOP penetration values determined without the air-balancing system are slightly higher. Tests with Welsh 7500-7 filter cartridges indicate that either steady-flow tests with $0.3-\mu \mathrm{m}$ DOP or conventional DOP man tests as proposed by the U.S. Bureau of Mines under Schedule $21 \mathrm{~B}^{2}$ overestimate filter performance. For quality-control and man-test 
applications of Welsh 7500-7 filters, a 0.5$\mu \mathrm{m}$ monodisperse aerosol would provide a more critical test. Comparative data for MSA Type-s and Welsh 7500-7 filters imply that individual test procedures may have to be developed for each type of respirator filter cartridge.

Figure 8 presents aerosol penetration of Whatman 41 medium as a function of particle size at cyclic-flow rates of 415,622 , and $830 \mathrm{~kg}-\mathrm{m} / \mathrm{min}$ and a steady-flow rate of 16 liters/min. This type of filter was used to compare respirator filter media and a medium that is often used for air sampling. Significant differences in penetration are seen below 1.5- $\mu \mathrm{m}$ particle size. Penetration varies from approximately 1 to $40 \%$ throughout the entire size and work-effort range tested. Although 0.5- $\mu \mathrm{m}$ particles cause peak penetration to occur during $c_{y}-$ clic flow, this maximum penetration increases as the cyclic-flow work rate decreases. This would be expected because the time-averaged mean velocity at the higher

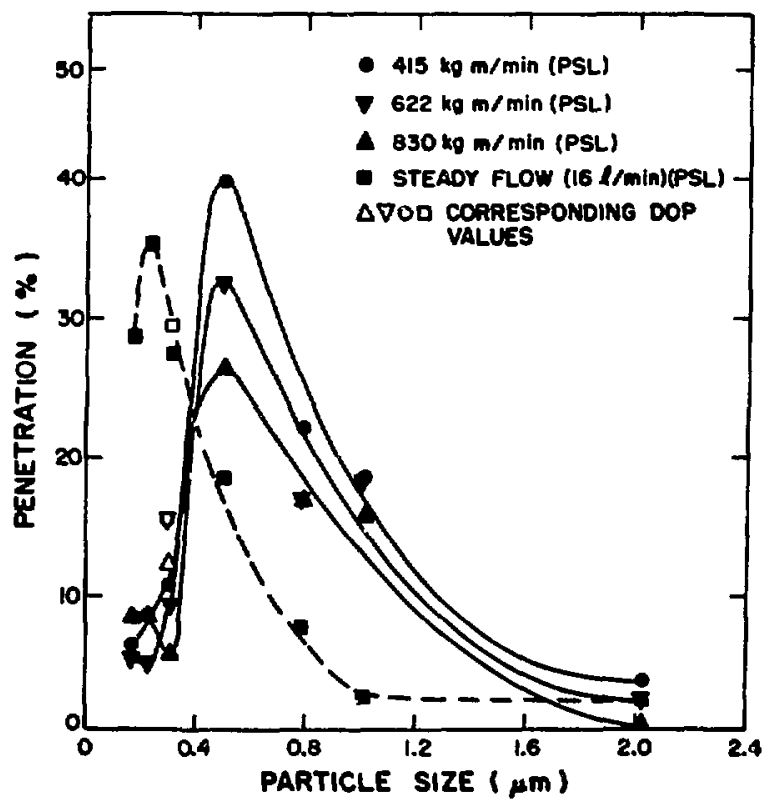

Fig. 8. Aerosol penetration of Whatman 41 filter medium at cyclic-flow work rates of 415,622 , and $830 \mathrm{~kg}-\mathrm{m} /$ min.

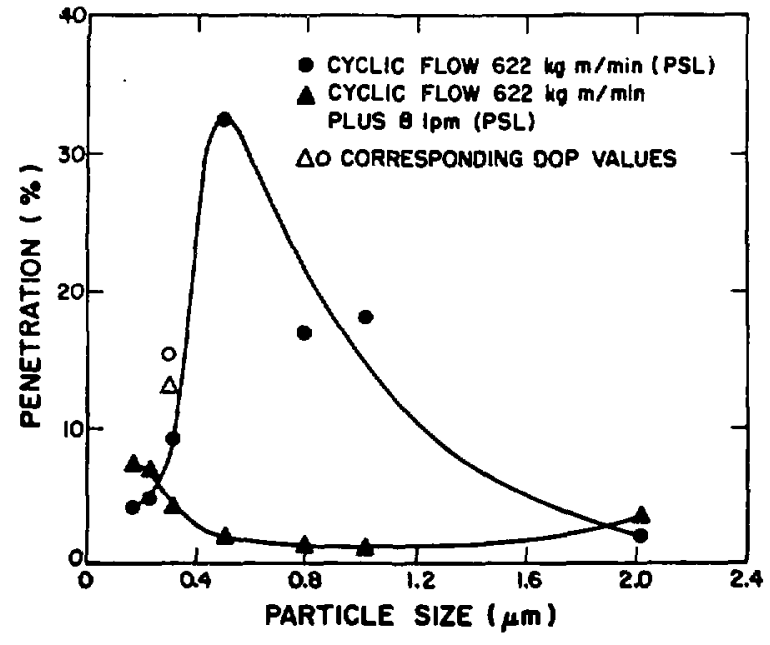

Fig. 9. Aerosol penetration of Whatman 41 filter medium at cyclic-flow work rates of $622 \mathrm{~kg}-\mathrm{m} / \mathrm{min}$ and $622 \mathrm{~kg}-\mathrm{m} /$ min plus 8 liters/min.

work rates is greater, and impaction mechanisms can become more effective. Penetration decreases below $0.5 \mu \mathrm{m}$, as was true for Welsh 7500-7 filter cartridges. This is probably because diffusion mechanisms become more effective. DOP penetration is, again, slightly higher than polystyrene latex penetration. At 16 liters/min steady flow, 0.234-um polystyrene latex produces peak penetration, in agreement with previous experimental tests. 12 Below $0.4 \mu \mathrm{m}$, steady flow appears to give an underestimate of filter performance and the converse is true above $0.4 \mu \mathrm{m}$. These isats indicate that performance tests with $0.5-\mu \mathrm{m}$ monodisperse aerosols or a polydisperse aerosol with a unit density $0.5-\mu \mathrm{m}$ count median dianeter would be desirable. The tests also indicate, again, that each type of filter is different, and individual performance tests should be prescribed for each type of filter and its use.

Figure 9 shows the relationship of true cyclic flow to cyclic flow plus an 8-liter/ nin sampling rate (man-test condition) at a work rate of $622 \mathrm{~kg}-\mathrm{m} / \mathrm{min}$. The true cyclicflow rate produced with the air-balancing 
system gives significantly higher penetration values than those found when the balancing system is not employed. Although this type of filter is not used in respiratory protection, these data indicate that the DOP man-test methods suggested by the Bureau of Mines Schedule 21 B should be reevaluated. Peak penetration occurs at less than 0.2-um particle size without the airbalancing system. This, again, could be because impaction mechanisms become more effective at smaller particle sizes owing to the added velocity. Dor values, with and without the air-balancing system do not differ significantly.

\section{SUMMARY}

Practical and theoretical performance of filtration media used for respirator filter cartridges have usually been investigated under steady- or constant-flow conditions. Steady-flow tests are currently used to predict future cartridge performance under various cyclic-flow conditions.

We tested aerosol penetration as a function of particle size using two respirator filter cartridges and one air-sampling medium during both steady flow and cyclic flow that simulated differing human breathing efforts. Maximum penetration of all filters does not occur at the same particle size during either cyclic or steady flow. Maximum penetration also occurs at a different particle size during cyclic flow as compared to steady flow. Generally the maximum penetration during cyclic flow is considerably higher than corresponding steadyflow values. Penetration of respirator cartridges and air-sampling filters by aerosols larger than $1.0 \mathrm{\mu m}$ was found to increase at some work rates. This is significant because the total mass of these particles is considerably greater than that of $0.3-\mu m$ particles.

Steady-flow rates may provide a consiclerable overestimate of filter performance. True cyclic flow that is close to the exact human breathing pattern, as opposed to true flow plus an 8 -liter/min sampling rate, is a more accurate method of estimating overall respirator performance.

The general implication of this study is that test procedures for assessing acceptance criteria as well as personnel protection should be re-evaluated. Because all filters are different, a specific set of test procedures should be prescribed for each type of filter. These tests should be performed so as to simulate an individual's "true" breathing pattern.

\section{REFERENCES}

1. E. C. Hyatt, Ed, "Respiratory Protective Devices Manual," (American Industrial Hygiene Association, 1963).

2. "Respiratory Protective Devices; Tests for Permissibility." Department of the Interior, Bureau of Mines, Federal Register, 36, No. 47 (Wed. March 10, 1971), Pp. 4652-4680.

3. L, Silverman, T. Plotkin, L. A. Sawyers, and A. Yancy, "Air Flow Measurements on Human Subjects With and without Respilatory Resistance at Several Work Rates," Arch. Ind. Hyg. Occupational Med. 3:461 (May 1951).

4. H. S. Jordan and L, Silverman, "Effect of Pulsating Air Flow on Fiber Filter Efficiency," Harvard School of Public Health, NYO Report 4814 (1961).

5. T. J. Rowland, "Study of Aerosol Filtration Characteristics Under Steady and Pulsating Flow Conditions," Master of Science Thesis, The University of Arkansas, Little Rock, Arkansas (1970).

6. M. E. Wilson and D. C. Harrod, "Development of Mechanical Breather for Evaluation of Respiratory Equipment," AMA Archives of Industrial Heaith, 13, 561$566(1956)$.

7. K. T. Whitby, D, A. Lundgren, and R. C. Jordan, "Homogeneous Aerosol Generators." Int. J. Air and water Poll. 9 . 263-267 (1965).

B. J. G. Hughes, personal communication, 1971.

9. R. G. Stafford and H, J. Ettinger, "Comparison of Filter Media Against Liquid and Solid Aerosols." Amer. Ind. Hyg. Assoc. J. 32, 319-325 (May 1971).

10. Soong, An-Liang, "The Charge on Latex Particles Aerosolized fxom Suspensions 
and Their Neutralization in a Tritium De-ionizer," University of Rochester Atomic Energy Project report UR-49-1000 (1968).

11. K. T. Whitby and B. Y. H. Liu, Aerosol Science, C. N. Davies, Ed. (Academic Press, New York, 1966), Chap. III.

12. R. G. Stafford and H. J. Ettinger, "Filter Efficiency as a Function of Particle Size and Velocity," Atmospheric Environment $6,353-362$ (1972).

13. U.S. Army Chemical Corps and U.S. Navy Bureau of Ships, "Filter Units, Protective Clothing, Gas Mask Components and Related Products: Performance Test Methods," Report MIL-STD-282 (May 1956).

14. U.S. Atomic Energy Commission, Handbook on Aerosols, Washington, D. C. (1950), Chap. 7 .
15. R. D. Hiebert, R. G. Stafford, and L. L. Pollat, "Improved Light-Scattering Photometer for Air-Filtration System Studies," Los Alamos Scientific Laboratory report LA-4626-MS (February 1971).

16. I. Langmuir, W. H, Rodebush, and $V . K$. LaMer, "Filtration of Aerosols and the Development of Filter Materials," office of Scientific Research and Development report OSRD 865 (September 1942).

17. "Threshold Iimit Values of Airborne Contaminants and Physical Agents with Intended Changes Adoptec by American Congress of Governmental Industrial Hygienists" (1971). 